\title{
Multifunctional anti-wax coatings for paraffin control in oil pipelines
}

\author{
Jie Bai ${ }^{1} \cdot \mathrm{Xu} \mathrm{Jin}{ }^{2} \cdot J u n-T a o \mathrm{Wu}^{1}$ \\ Received: 8 January 2018 / Published online: 15 April 2019 \\ (c) The Author(s) 2019
}

\begin{abstract}
Paraffin deposition is a severe global problem during crude oil production and transportation. To inhibit the formation of paraffin deposits, the commonly used methods are mechanical cleaning, coating the pipe to provide a smooth surface and reduce paraffin adhesion, electric heating, ultrasonic and microbial treatments, the use of paraffin inhibitors, etc. Pipeline coatings not only have the advantages of simple preparation and broad applications, but also maintain a long-term efficient and stable effect. In recent years, important progress has been made in research on pipe coatings for mitigating and preventing paraffin deposition. Several novel superhydrophilic organogel coatings with low surface energy were successfully prepared by bionic design. This paper reviews different types of coatings for inhibiting wax deposition in the petroleum industry. The research prospects and directions of this rapidly developing field are also briefly discussed.
\end{abstract}

Keywords Paraffin control $\cdot$ Coatings $\cdot$ Surface energy $\cdot$ Bionic design $\cdot$ Wettability

\section{Introduction}

Crude oil is known as "black gold" and is also called as "the blood of modern industry." It not only benefits human beings in terms of energy, but also is a very important chemical raw material. Crude oil is a thick, dark brown liquid, a mixture of different hydrocarbons. Paraffin is one of the important components in crude oil. Paraffin is composed of straightchain saturated hydrocarbons, of which the majority are $n$-alkanes with a small amount of isoparaffins, naphthenes and extremely few aromatic hydrocarbons. Paraffin generally has a melting point of $30-70{ }^{\circ} \mathrm{C}$. Crude oil in China is a heavy conventional oil with a high pour point, high wax content, low content of heptane asphaltene and a relative density between 0.85 and 0.95 (Lu and Zhang 1980; Tissot et al. 1978).

\section{Edited by Yan-Hua Sun}

Jun-Tao Wu

wjt@buaa.edu.cn

1 Key Laboratory of Bio-Inspired Smart Interfacial Science and Technology of Ministry of Education, School of Chemistry, Beihang University, Beijing 100191, People's Republic of China

2 PetroChina Research Institute of Petroleum Exploration and Development (RIPED), Beijing 100083,

People's Republic of China
In the process of petroleum exploitation and transportation, with a decrease in temperature and pressure to a certain extent, the wax dissolved in the crude oil will crystallize and precipitate, then adsorb and deposit in the inner wall of the tubing, casing and other equipment. The problem is widespread in oil fields all over the world ( $\mathrm{Li}$ et al. 2014). Wax deposition in the inner wall of petroleum pipelines will cause the effective flow area to be reduced or blocked, thus increasing the flow resistance and pump loads and affecting the service life of equipment such as sucker rods. This will not only reduce the efficiency of work, resulting in huge economic losses, but also damage the operating equipment. In severe cases, production must be stopped to remove wax from the pipeline (Correra et al. 2007; Towler and Rebbapragada 2004; Wang and Zhang 1999; Venkatesan et al. 2003).

In order to reduce or eliminate paraffin deposition, the commonly used methods are mechanical cleaning (Poole et al. 2008), coating the pipe to reduce paraffin adhesion (Dotto et al. 2006), electric heating (Samigullin et al. 2016; Danilović et al. 2010; Zheng 2012), ultrasonic treatments (Seow 1991; Gonçalves et al. 2010; Tung et al. 2001), the use of paraffin inhibitors (Gilles et al. 2015; Yang et al. 2015; Jung et al. 2016; Ridzuan et al. 2016) and microbial removal (He et al. 2003; Liu et al. 2012; Xiao et al. 2012; Yi et al. 2009), etc. Among them, mechanical cleaning uses a special scraper to remove paraffin and soft wax deposits from the inner wall of the pipeline. It is a primitive and 
simple method. What is more, the mechanical cleaning, electric heating and ultrasonic treatments are inefficient and energy-consuming, and thus, it is difficult to perform them well in harsh environments such as deep-sea pipelines (Aiyejina et al. 2011; Sun et al. 2014). However, coating the pipes may inhibit and eliminate the formation of paraffin deposits by putting one or more coatings on the inner wall before use. Specially, anti-wax coatings not only have the advantages of simple preparation and broad application, but also can maintain long-term efficiency and a stable effect, which has wide application prospects. In recent years, many achievements have been made in this field at both home and abroad, especially in the field of bioinspired intelligent interface materials. In this paper, recent research into different kinds of coatings to inhibit wax deposition in the petroleum industry has been summarized. The research prospects and directions of this rapidly developing field are also briefly reviewed.

\section{Paraffin deposition mechanisms}

Paraffin deposition in petroleum pipelines is not only related to temperature, pressure and the composition of crude oil, but also influenced by other factors, such as flow velocity, pipeline material and design. It is really a complex process. In the early studies, the mechanisms of paraffin deposition were mainly divided into four categories, among which molecular diffusion is the dominant factor, followed by shear dispersion, Brownian diffusion and gravity sedimentation. In addition, asphaltenes are important constituents of waxy crude oil; the latest research shows that the presence of asphaltenes has a significant impact on the stratification of paraffin deposits.

\subsection{Molecular diffusion}

Burger et al. (1981) investigated wax deposition mechanisms in the Trans-Alaska Pipeline and believed that the deposition was a result of lateral transport by molecular diffusion, shear dispersion and Brownian diffusion (Burger et al. 1981). However, Brown et al. (1994) found that shear dispersion had no significant effect on paraffin deposition based on experimental measurements and field operating experience, and no paraffin deposition was observed under zero-heat flux conditions (Brown et al. 1994). Azevedo and Teixeira (2003) proposed that molecular diffusion of paraffin is the major contributor to wax deposition, and Brownian diffusion, shear dispersion and gravity sedimentation are minor and negligible (Azevedo and Teixeira 2003).

Studies of paraffin deposition in petroleum pipelines show that molecular diffusion plays a leading role, especially in the low-temperature environment of abyssal sea pipelines.
As the pipelines cool below the critical temperature, a temperature gradient is generated in the cross section, where the temperature near the tube wall is the lowest as well as the lowest solubility of paraffin molecules. This concentration gradient due to the temperature gradient is the power of paraffin molecules to diffuse from the core of petroleum to the inner wall (Tian et al. 2014; Duan et al. 2011). Paraffin molecules start to move out of the petroleum and form a network of colloidal structures with some petroleum molecules and then adhere to the inner wall of the pipeline. The initially formed paraffin sediments contain some small petroleum molecules; thus, they are relatively low in hardness. Subsequently, a large number of paraffin molecules continue to diffuse to the tube wall and adsorb on the initial sediments, resulting in an increased hardness of paraffin. Finally, more paraffin will be deposited on the inner wall, which brings serious problems to crude oil production and transportation (Zhang and Liu 2010; Hamouda and Ravney 1992).

\subsection{Shear stripping and aging}

In recent years, progress has been made on understanding paraffin deposition in petroleum pipelines. On the basis of molecular diffusion, shear stripping and aging have gradually been recognized by the majority of researchers (Huang et al. 2016).

Different flow rates of the crude oil in pipelines show different flow states. When the crude oil flows at a low velocity, it moves in a direction parallel to the tube axis. The maximum flow velocity of the fluid is at the center of tube, and the minimum is near the wall. However, when the flow rate increases gradually, the flow pattern of crude oil will begin to undulate. The frequency and amplitude of oscillation increase with an increase in the flow rate, which is called transient flow. When the flow rate of the crude oil increases further, the streamline is no longer clear. There are many small eddies in the flow field, and the state is called turbulent flow. Under turbulent flow, the movement of crude oil in turbulent state has disorder, and it will produce a certain shear effect on the deposits in the inner wall. The faster the flow rate is, the stronger the shear action is. The shear stripping is the phenomena that the shear stress is large enough to destroy the structure of the deposited paraffin. It will peel off some of the sediments. Rashidi et al. studied the relationship between the paraffin deposition rate and the crude oil flow rate and found that the paraffin deposition rate increased with the flow rate in the low flow stage. When the flow rate exceeded a critical value, the paraffin deposition rate would decrease rapidly. The experimental results proved the importance of shear stripping in the paraffin deposition in petroleum pipelines (Rashidi et al. 2016).

Fogler's research group initially proposed the aging of wax deposits (Lu et al. 2012; Singh et al. 2000). Through 
a great number of experimental studies, they found that the wax content and hardness of the deposits increased gradually with deposition time in the process of wax deposition. Experimental studies showed that at the beginning of wax deposition, wax-oil gels were formed on the inner wall because the temperature of the inner wall of the pipeline was lower than the crude oil. These wax-oil gels contained most of the oil trapped in a 3-D network structure of wax crystals as a porous media. As the oil content was high, the hardness was still relatively low. Subsequently, the wax molecules in crude oil continued to diffuse and deposited to form wax-oil gels, gradually increasing the wax content of the deposited layer. At the same time, the oil content decreased gradually, but the mass fraction was higher than the oil in the pipe core, which resulted in the reverse diffusion of the oil layer from the sedimentary layer to the pipe center. The diffusion of wax molecules and counter-diffusion of petroleum molecules resulted in an increase in the wax content and hardness of the deposition layer. The phenomenon is called the aging of the deposited wax layer, and it has been recognized by the majority of researchers.

In the process of petroleum transportation, according to the phase composition of crude oil, it can be divided into single-phase flow and multiphase flow. The single-phase flow is an ideal condition. It has been confirmed that if there is no water or gas in crude oil, only the single flow characteristic is considered. In the single-phase (oil) flow, molecular diffusion is the main mechanism of wax deposition, and the shear stripping and aging have drawn more and more attention. However, the multiphase flow state is closer to the actual situation, including oil-water two-phase, oil-water-gas three-phase, oil-water-gas-sand and other multiphase situations. Wax deposition mechanisms under multiphase flow conditions are not very well understood. At present, our understanding is mainly based on the mechanisms of the single-phase flow; therefore, it needs to be further studied (Hernandez et al. 2004; Couto et al. 2008; Sarica and Panacharoensawad 2012).

\subsection{Effects of asphaltenes}

Asphaltenes are the heaviest and the most polar components in crude oil, and they are also important components in waxy crude oil (Lei et al. 2016). The latest research shows that the presence of asphaltenes has a significant impact on the stratification of wax deposition. $\mathrm{Li}$ et al. studied the phenomenon of wax deposits formed by synthetic waxy oil by direct observation, DSC tests and component analyses with a new wax deposition device ( $\mathrm{Li}$ et al. 2016). It was found that asphaltene played a role as a paraffin inhibitor and could significantly inhibit the paraffin deposition rate. When no asphaltene was present in waxy oil, paraffin deposition was formed by a thick wax-oil gel, and no stratification phenomena were found. With the addition of asphaltenes in waxy oil, an obvious two-layer stratification phenomenon occurred in the wax deposit. According to the remarkable difference of structural strength, the two layers could be clearly identified. The outer layer was very soft and easy to be scrapped. However, the inner deposit was very compact and hard and required sharp instruments to scrape it away. Yang et al. also investigated the effect of asphaltenes on the stratification in wax deposits (Yang et al. 2016). The results showed that there was interaction between asphaltenes and wax molecules, and the asphaltenes were enriched in the wax deposit layer by Brownian diffusion. The existence of asphaltenes changed the morphology of wax crystals (spherical flocs), which is due to the diffusion of asphaltenes and wax molecules. Both the molecular diffusion of wax and the Brownian diffusion of asphaltenes lead to the formation of a two-layer wax deposit, which greatly inhibits later wax deposition.

In order to solve the serious wax deposition in petroleum pipelines effectively, research and development of anti-wax technology has become particularly important. Among the various methods to prevent wax deposition, anti-wax coating has the most potential and is a valuable method because of its simplicity, efficiency and durability. Moreover, the multifunctional aspects of anti-wax coating can not only inhibit wax deposition, but also utilize other properties of the coating, such as corrosion resistance and mechanical stability.

\section{Anti-wax coatings}

Anti-wax coatings are methods to reduce or prevent wax deposition by coating an organic or inorganic material on the inner wall of oil pipelines. Compared with mechanical cleaning and paraffin inhibitors, the anti-wax coatings not only have the advantages of simple preparation and broad application, but also can maintain a long-term efficient and stable effect. There is no longer a need to regularly clean the pipes or to add paraffin inhibitors. Moreover, the anti-wax coatings can also inhibit the corrosion of metal and play a crucial role in protection. The anti-wax coatings that have been studied so far can be divided into the following three categories: low surface energy coatings, bioinspired superhydrophilic coatings and novel organogel coatings.

\subsection{Low surface energy coatings}

In the early research into coatings for paraffin deposition control, the researchers believed that smooth surface or low surface energy coatings can effectively inhibit paraffin deposition. Therefore, in a large number of experiments, the inner walls of pipes were coated with low surface energy polymer composite coatings, and their properties to inhibit paraffin 
deposition were investigated by controlling the free energy of the substrate surface (Dotto and Camargo 2010).

Jessen and Howell (1958) studied the paraffin deposition on the surface of different pipe materials (Jessen and Howell 1958). It was found that the paraffin deposition on the surface of smooth plastic was much smaller than that on a steel surface and maintained a low paraffin deposition for a long time. Jorda (1966) conducted paraffin deposition experiments on metal and plastic surfaces, with other conditions unchanged, only studying the effect of coating surface roughness on paraffin deposition. The experimental results showed that a smooth phenolic resin surface exhibited an excellent capacity of reducing paraffin deposits compared with epoxy resin and polyurethane surfaces, while the roughness of a steel or plastic surface increased the amount of paraffin deposits. They suggested that coatings for paraffin deposition prevention should have a smooth surface, high polarity, high gloss and flexibility, so as to provide long-term resistance to paraffin deposition in oil wells (Jorda 1966).

With the development and application of polytetrafluoroethylene (PTFE), Zhang et al. applied fluoropolymer and other resin materials to the inner wall of the tubes (Zhang et al. 2002). The aim was to compare the relative effects of resin coatings on preventing paraffin accumulation and reducing friction drag on the surface of coatings. They studied the effects of eight coatings, such as alkyd resins, methacrylate copolymers, vinylidene fluoride-chlorotrifluoroethylene copolymers, polyvinylidene fluoride and room-temperature vulcanized silicone rubbers. The experimental results showed that fluoropolymer and vulcanized silicone rubber coatings with low surface energy had significant effects on drag reduction and paraffin deposition prevention. The silicone rubber coating could achieve an efficiency of up to $75 \%$ in paraffin deposition prevention and could reduce drag by $22 \%$ in crude oil at $26^{\circ} \mathrm{C}$.

In order to meet the actual working conditions in crude oil transportation, Quintella et al. evaluated the influence of the flow state of crude oil on the inhibition of paraffin deposition when using three types of polymer coatings (Quintella et al. 2006). Figure 1 shows the structures of three coatings: polypropylene (PP), high-density polyethylene (HDPE) and ethylene vinyl acetate copolymer (EVA28) with an oxygen content of $28 \%$. It was found that the low polarization of EVA28 was due to the crude oil oxygen content and the stronger interaction between crude oil and surface groups. The interfacial tension between the crude oil and the coatings was $12 \%$ and $17 \%$ higher for EVA28 and HDPE, respectively, than for that of PP under static conditions. Under flow conditions, the interaction of EVA28 and HDPE with crude oil increased by $79 \%$ and $43 \%$, respectively, compared to PP. Therefore, the tendency of PP to inhibit paraffin deposition was higher, and the effect on crude oil in the flow state was better. This is due to the fact that the methyl groups on the

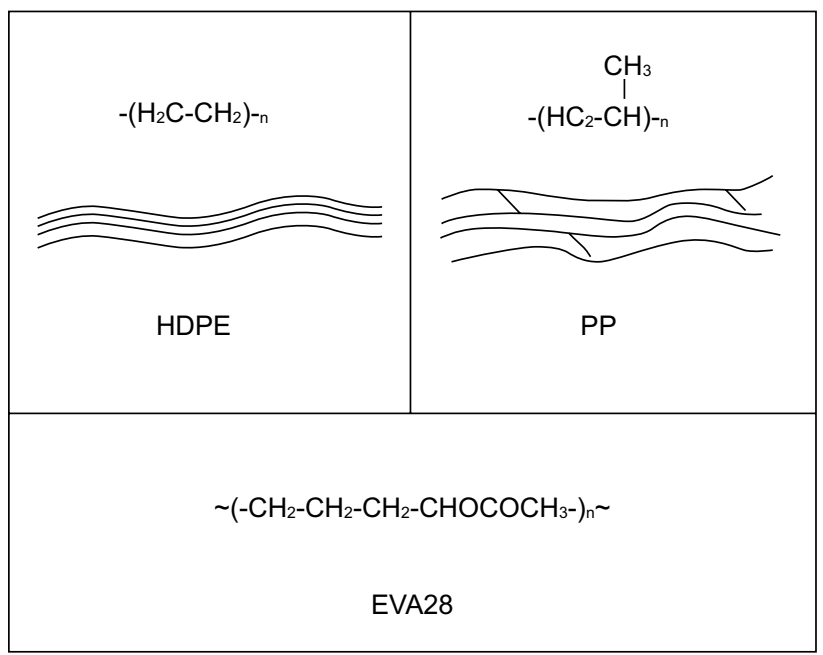

Fig. 1 Chemical structure of the anti-wax coatings (after Quintella et al. 2006)

surface of the PP reduce the surface density of the hydrogen atoms and hinder the interaction between the alkyl groups and the surface in crude oil.

Rashidi et al. (2016) studied the effect of the surface roughness of the coating in a submarine pipeline on the deposition of paraffin in Malaysia with polyvinyl chloride (PVC) and ethylenetetrafluoroethylene (ETFE), and the influence of crude oil cooling rate and flow velocity of different coatings of paraffin deposition (see Fig. 2). It was found that the ETFE coating with the least roughness had the best control on paraffin deposition. Moreover, the faster the cooling rate of crude oil is, the faster the deposition rate of paraffin is. However, at low flow rates, the deposition rate of paraffin increased with the flow rate, and when the flow rate was greater than a critical value, the deposition rate decreased rapidly. This was because at lower velocities range, the crude oil is in laminar flow and stays in the pipeline for a longer time. This resulted in more heat loss and a rapid decrease in the temperature of the crude oil, leading to paraffin deposition (Rashidi et al. 2016).

The study of low surface energy anti-wax coatings has been very thorough. Many new coatings with very low surface energy have been developed, most of which are derivatives of polytetrafluoroethylene. In the field of modern petroleum industry, most of the coatings used are low surface energy coatings, which have good anti-wax effects. However, in order to adapt to harsher service environments, it is urgent to develop more excellent anti-wax coatings, and the mechanical properties and corrosion resistance of coatings also need to be improved. Many researchers have shifted the focus from low surface energy to the wettability of bioinspired superwetting interface materials, and a series of new developments have been achieved. 

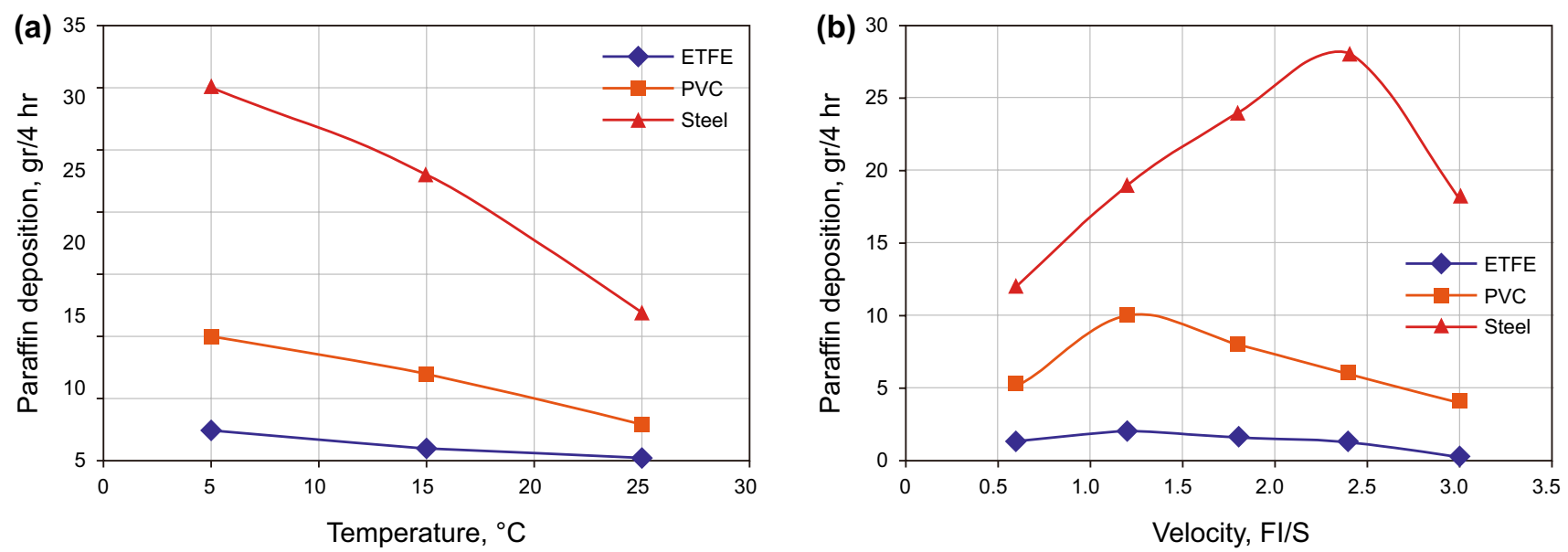

Fig. 2 Effect of temperature (a) and velocity (b) on rate of paraffin deposition (after Rashidi et al. 2016)

\subsection{Bioinspired superhydrophilic coatings}

In recent years, a large number of researchers have applied the idea of bionics to the study of functional materials and have tried to learn from and imitate the effective structures in nature after their long evolution. These include the superhydrophobic structure on the upper surface of leaves (Gong et al. 2012, 2015a; Cheng et al. 2011), the superoleophobic structure of the lower surface of the lotus leaf and the surface of fish skin (Liu et al. 2009; Ma et al. 2014; Gao et al. 2016; Chen et al. 2016), the water-collecting structure of the back of beetles (Parker and Lawrence 2001), the back groove of Opuntia cactus and spider silk structure (Gong et al. 2015b; Bai et al. 2015) and organic and inorganic composite structure of pearl shell layers (Guo et al. 2016; Xu et al. 2013). Among these, some researchers focused on pipeline anti-wax works, and research results are quite abundant.

Charles (1986) treated carbon steel with three sulfur oxides to obtain a highly hydrophilic surface (Charles 1986). The surface can form a layer of water film between the interface of the crude oil and the metal to slow down the deposition of paraffin, and reduce the paraffin adhesion, thus causing paraffin crystals to be easily washed away by the fluid. They suggested that it can be widely applied and can alleviate paraffin deposition on the inner wall of crude oil pipes for a long time. Li et al. (1997) investigated the effects of glass coating and a carbon steel surface on the deposition of paraffin in the presence of multiphase oil and water for the production and transportation of crude oil in the Jilin Oilfield. The results showed that for carbon steel coated with hydrophilic glass in water-bearing crude oil, wax deposition decreased with the water content. When the water content exceeded $60 \%$, the crude oil became oil-water emulsion. At this time, a stable water film can be formed between the crude oil and the glass tube wall. The film can inhibit the deposition of wax in the glass tube wall, thus reducing the deposition of paraffin (Li et al. 1997).

In addition to ordinary glass coating, attention has also been drawn to hydrophilic $\mathrm{TiO}_{2}$ particles. Yu et al. (2001) prepared ultra-hydrophilic $\mathrm{TiO}_{2} / \mathrm{SiO}_{2}$ composite films by the sol-gel deposition method, which can be used to prevent fouling and sludge precipitation in wastewater treatment. As the surface contains a large number of hydroxyl groups, the water contact angle of the film can be as low as zero (Yu et al. 2001). Bae et al. (2006) prepared antifouling nanocomposite films by electrostatic self-assembly using $\mathrm{TiO}_{2}$ nanoparticles and anionic sulfonated poly(ether sulfone) (Bae et al. 2006). The addition of $\mathrm{TiO}_{2}$ particles improves the hydrophilicity of the membrane and inhibits the hydrophobic interaction between the film surface and organic pollutants. Although the effects of the crude oil in the petroleum pipeline can be blocked, it is believed that the hydrophilic properties of the composite membrane may be contaminated by other compounds in petroleum pipelines, which can facilitate subsequent paraffin deposition and which remains to be studied.

Theories about water films on coating surfaces have appeared frequently in recent years. Guo et al. (2012a, b) treated the surface of galvanized carbon steel substrate with sodium silicate and a mixed acid solution (Guo et al. 2012a). A chemical conversion coating was formed. The coating was mainly composed of $\mathrm{Zn}, \mathrm{O}, \mathrm{Si}$ and other elements. This coating is hydrophilic in air and superoleophobic underwater. Combined with the rough structure of the surface, the conversion film was first adsorbed in water and formed a layer of water film. In water, the contact angle between the water film and liquid paraffin was $160^{\circ}$, and the water film had good non-adhesion, which resulted in a very good anti-wax effect. Subsequently, Guo et al. investigated the paraffin deposition resistance of phosphorus-containing chemical conversion 
films obtained at different temperatures $\left(\mathrm{H}: 80-90{ }^{\circ} \mathrm{C}, \mathrm{M}\right.$ : $50-60{ }^{\circ} \mathrm{C}$, R: room temperature) (Guo et al. 2012b). The results show that the conversion coating $(R)$ obtained at room temperature had the best anti-wax effect which can reach $80 \%-95 \%$. They found that the phosphorus chemical conversion film on the carbon steel surface was hydrophilic (with a water contact angle of $22^{\circ}$ ), the surface morphology of the conversion film obtained at room temperature had the largest roughness, and a stable water film could be formed in the water to prevent paraffin deposition on the membrane surface, as shown in Fig. 3.

The underwater superoleophobic system based on water film theory is better, and the nanometer composite structure on the surface of coating is becoming more important. Wang et al. (2013a, b) fabricated a pyrophosphate coating with a flower-like microstructure on the surface of carbon steel (Wang et al. 2013a). In the paraffin deposition experiment, it was found that the coating had good anti-wax performance, reaching about $80 \%$, and had good stability (see Fig. 4). They thought this is due to the wettability of the coating surface, underwater superoleophobicity (contact angle of oil droplets in water was $160^{\circ}$ ) and low adhesion of oil droplets (oil droplet rolling angle $7^{\circ}$ ). The essence is the synergistic effect of the hydrophilicity and the microstructure of the coating surface, so a stable water film can be formed to prevent the deposition of paraffin (see Fig. 5).

Wang et al. developed a chemical conversion film of ferric phosphate by in situ alternating deposition on the surface of carbon steel, which was inspired by the underwater superoleophobic properties and low adhesion structures on the surface of fish skin and clamshells (Wang

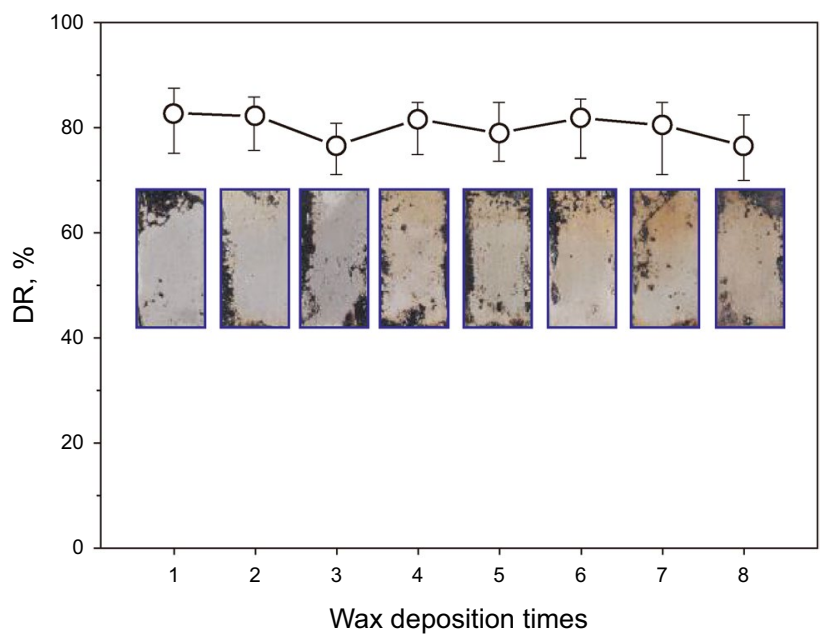

Fig. 4 Time stability of the anti-wax coating (after Wang et al. 2013a)

et al. 2013b). The film had the best effect in preventing wax deposition when the deposition time was greater than $2 \mathrm{~h}$. The surface of the conversion film was composed of hydrophilic amorphous iron phosphate and had a layered micro-nanocomposite structure exhibiting superhydrophilic behavior in air (with a water contact angle of $0^{\circ}$ ) and superoleophobic behavior (with an oil contact angle of $160^{\circ}$ ) in water. The characteristics of water in the surface adsorption can form a layer of water film. In paraffin deposition experiments, the deposition of paraffin in watercontaining crude oil can be effectively prevented, showing excellent self-cleaning properties (see Fig. 6).
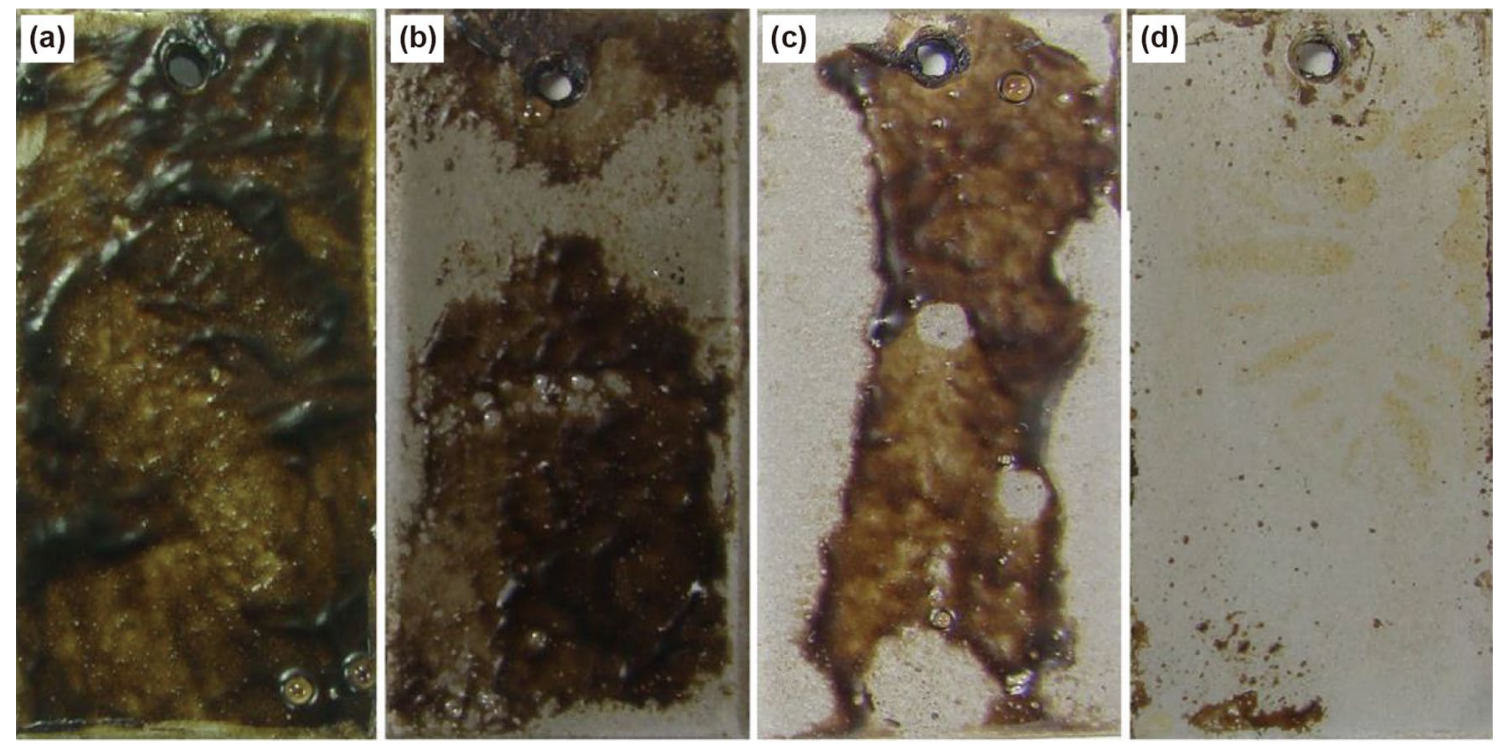

Fig. 3 Sample surface after wax deposition test. a Carbon steel, b H $\left(80-90^{\circ} \mathrm{C}\right)$, c $\mathrm{M}\left(50-60{ }^{\circ} \mathrm{C}\right)$ and $\mathbf{d} \mathrm{R}$ (room temperature) coating (after Guo et al. 2012b) 
Fig. 5 Schematic diagram of wetting state of oil droplets on the different substrates. a Carbon steel. b Conversion coating. c The self-cleaning mechanism for the conversion coating in water-contained crude oil (after Wang et al. 2013a)
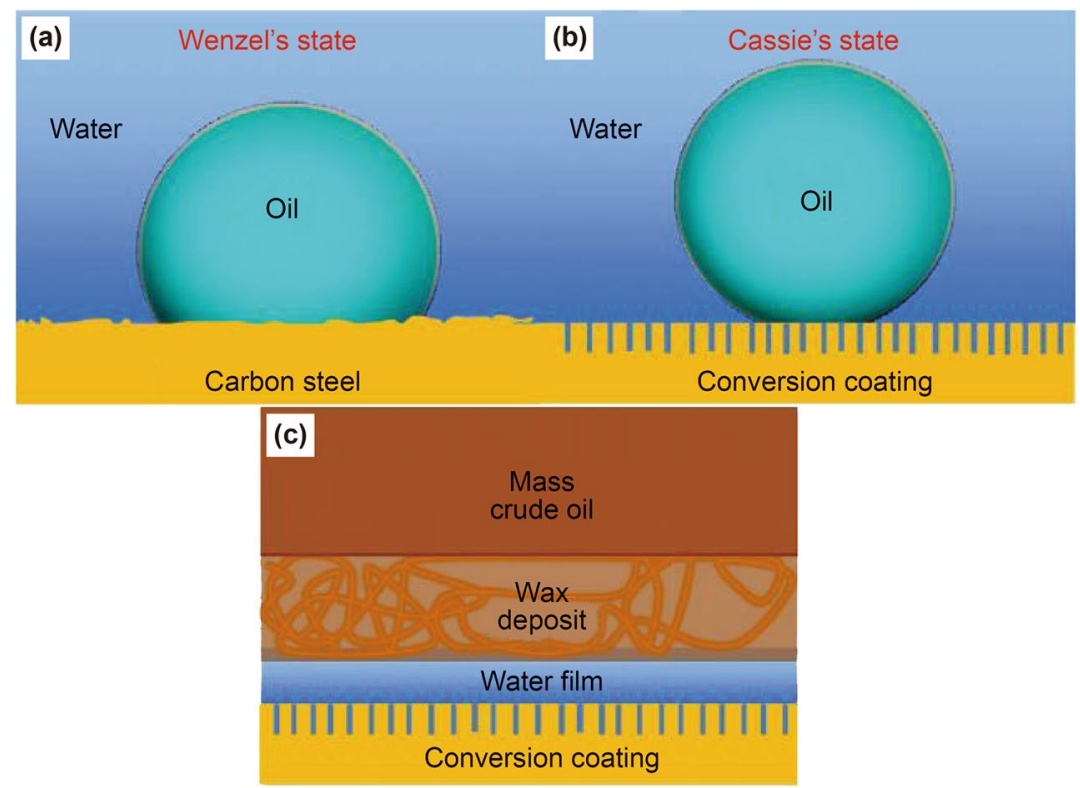

same time, the surface morphology of carbon steel became very rough, with a micro-nanocomposite structure, and the wax prevention effect was improved significantly. They investigated the influence of water content of crude oil on the anti-wax performance of coating. It was found that the anti-wax effect was very poor without water in crude oil. However, when the water content increased gradually, the coating could basically keep the anti-wax effect around $95 \%$.

Because a single anti-wax coating could not provide good corrosion resistance, Liang et al. prepared a composite coating on the surface of carbon steel, which had three layers of structure (Liang et al. 2015). As shown in Fig. 7, these structures from the bottom to the top are: (1) electrodeposited zinc film for improving corrosion resistance; (2) phosphating film for constructing a fish-scale surface morphology; and (3) silicon dioxide film for giving superhydrophilicity to coating surface. The special hydrophilic surface and micro-nanocomposite structure can capture a layer of water film on the surface and have underwater superoleophobic characteristics. In paraffin deposition experiments, the composite coating exhibited good resistance to paraffin deposition, which was attributed to the presence of a water film. Moreover, the corrosion resistance of the coating was greatly improved due to the existence of the zinc film, and the thermal stability and mechanical stability were excellent.

Liang et al. (2016a, b) prepared a phytic acid conversion coating on the surface of galvanized carbon steel (Liang et al. 2016a). The effect of $\mathrm{pH}$ on the deposition of paraffin in crude oil was studied. It was found that at $\mathrm{pH} 4$, the effect of the conversion film formed on the steel surface was significantly better than a zinc coating (see Fig. 8). They

the elements such as $\mathrm{Zn}, \mathrm{Ni}, \mathrm{Fe}$ and $\mathrm{P}$ were added at the 

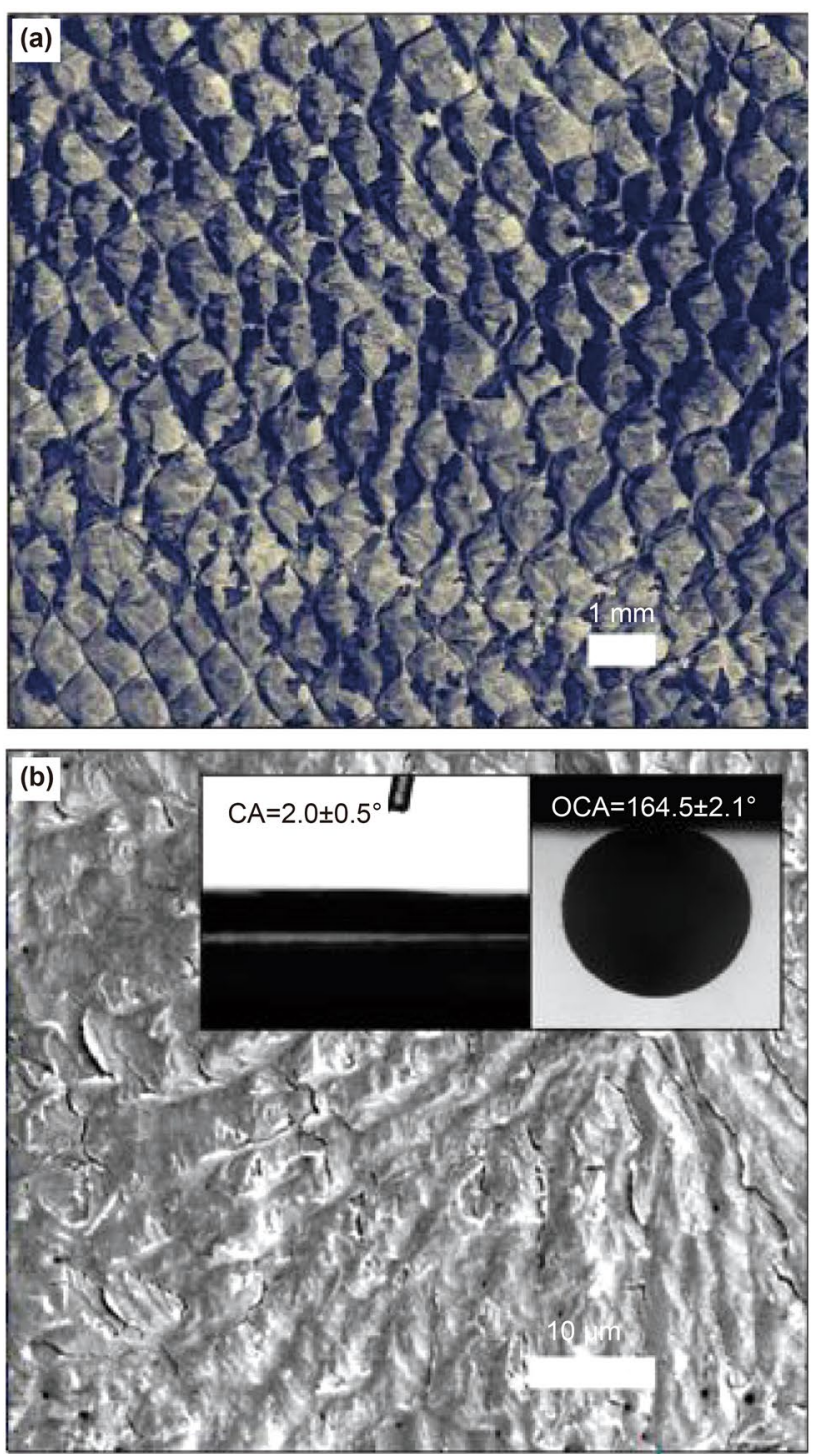

(c)

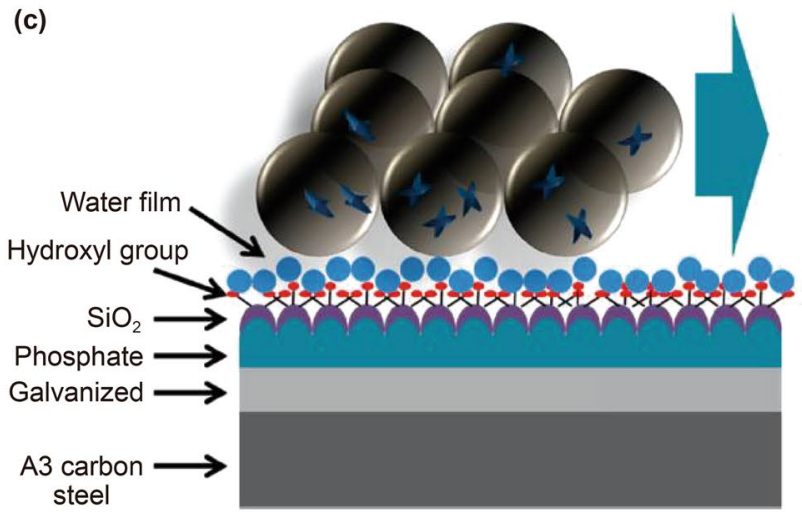

Fig. 7 Underwater superoleophobic composite coating with fishscale-like surface structure. a Digital image of real fish scales. b SEM image of a fabricated fish-scale-like composite coating. (The insets are digital images of the water contact angle and oil contact angle on the surface of composite coating.) c Schematic diagram of the prepared composite coating (after Liang et al. 2015) analyzed the components, morphology and wettability of the surface of the coating and found the conversion film on the surface had a micro-nanorough structure and showed the superhydrophilic (with a water contact angle of $0^{\circ}$ ) and underwater superoleophobic (oil contact angle of $162.3^{\circ}$ ). They suggested that the coating can adsorb a layer of water film in water, which is the main reason for preventing the deposition of paraffin.

Subsequently, Liang et al. proposed an environmentally friendly coating to prevent wax deposition (Liang et al. 2016b). They modified the surface of galvanized carbon steel with 4-isobutylbenzene acid. Because of the absence of any waste liquid in the process, an environmentally friendly conversion coating was obtained. They studied the effect of $\mathrm{pH}$ and soaking time on the properties of the coating. Results showed that after being soaked in the conversion solution $(\mathrm{pH}=4)$ for $20 \mathrm{~min}$, the characteristics of the coating underwater were superoleophobic (oil contact angle of $163^{\circ}$ ), with the best performance to prevent wax deposition and good corrosion resistance (see Fig. 9).

\subsection{Novel organogel coatings}

In addition to the low surface energy and bioinspired superhydrophilic coatings, recently some researchers have begun to reduce the drag between the surface and the interface, to prepare a new surface. This type of surface can achieve a state of ultra-low adhesion, which reduces the adhesion of the coating to wax and has a good effect on preventing wax deposition.

Yao et al. (2015) prepared a new type of organogel (OG) material by polydimethylsiloxane (PDMS) (Yao et al. 2015). They immersed rectangular slices of PDMS in crude oil (gasoline and diesel) for 1 day, so that oil molecules diffused into PDMS to expand it. Finally, it was transferred to the surface of carbon steel to study its performance to prevent wax deposition (see Fig. 10).

The results showed that the oil-treated PDMS had excellent resistance to paraffin deposition. This is mainly because the adhesive force between paraffin crystals and the surface of PDMS was very low and 500 times smaller than traditional materials. They believed that the PDMS organogel material can avoid uneven nucleation of paraffin on its surface. At the beginning of contact between liquid paraffin and the PDMS surface, liquid paraffin diffused into the oil layer on the surface, nucleated and crystallized, which greatly reduced the contact with the PDMS surface. The resulting microscopic composite structure had very low adhesion for paraffin crystals. Therefore, whether the crude oil is in the stationary or flowing states, the coating has excellent performance for reducing paraffin deposition.

The prepared PDMS organogel coating not only has good performance to prevent wax deposition, but also has a 
(b)
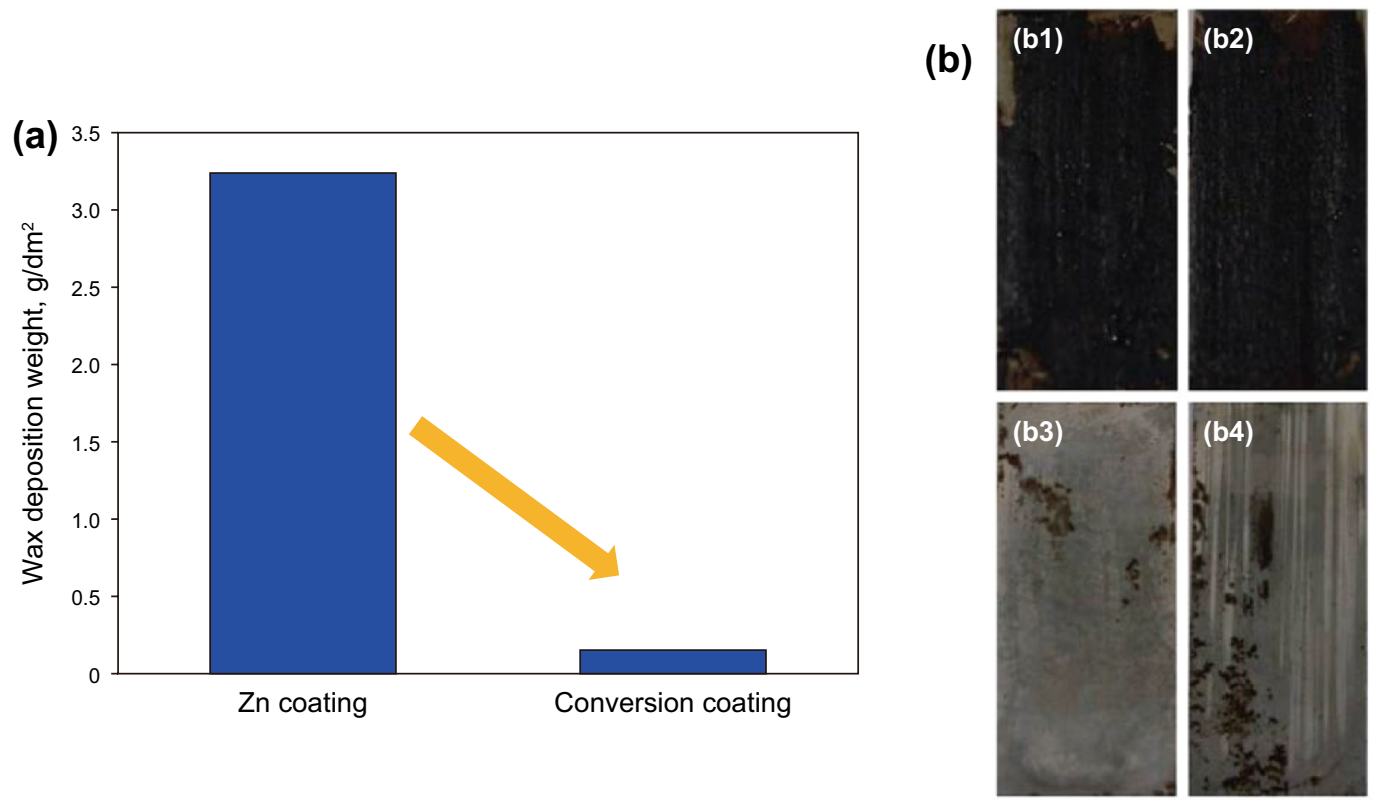

Fig. 8 a Comparison of wax deposition of $\mathrm{Zn}$ and conversion coatings. b The digital images of $\mathrm{Zn}$ coatings (b1, b2) and conversion coatings (b3, b4) after wax deposition test (after Liang et al. 2016a)
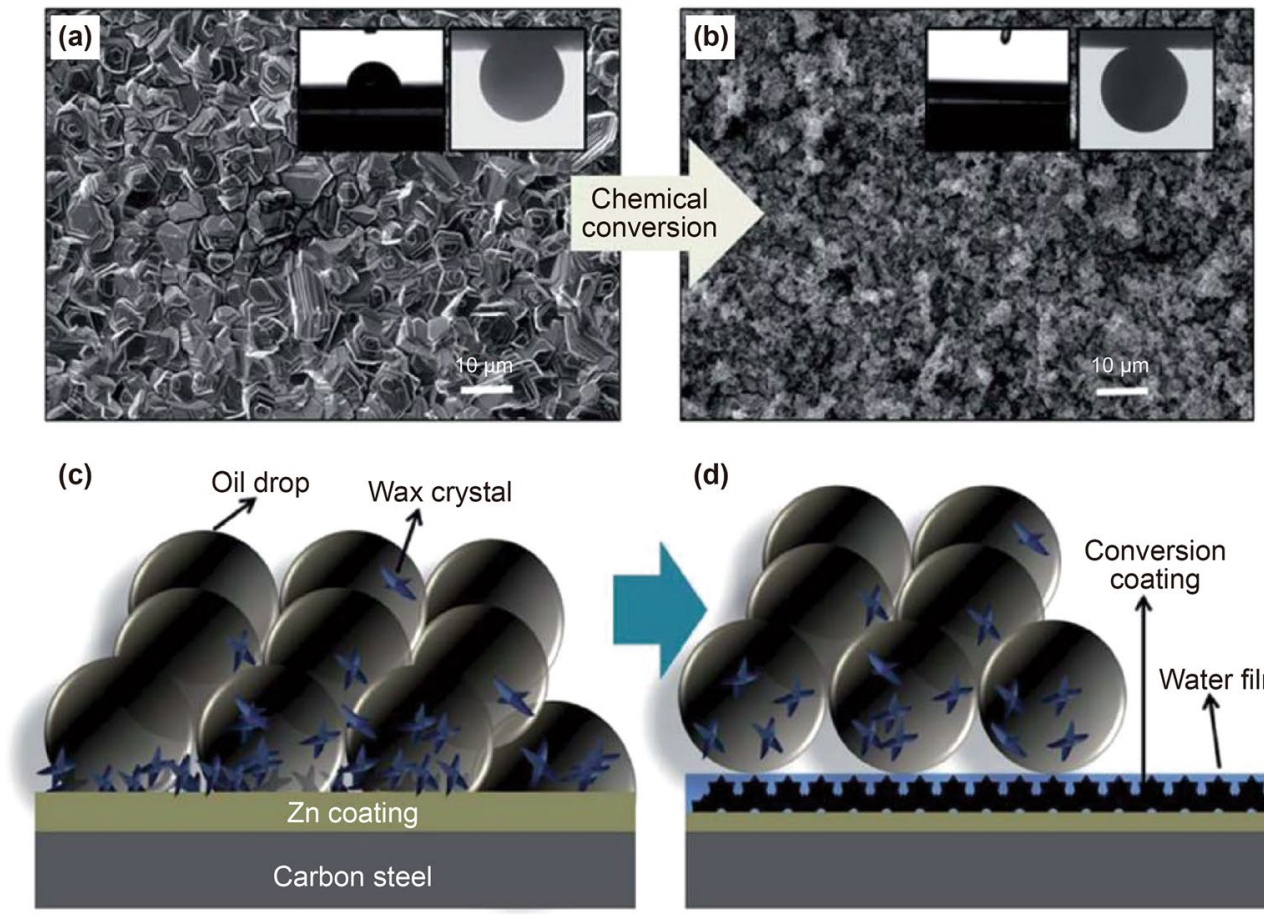

(d)

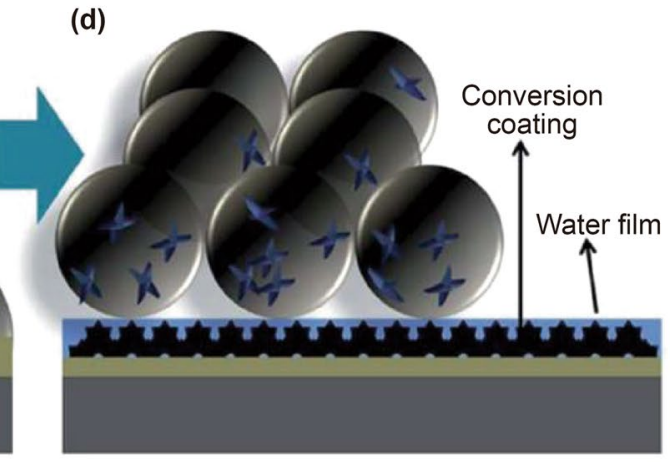

Fig. 9 Surface morphology, wettability of air and water of $\mathbf{a} \mathrm{Zn}$ and $\mathbf{b}$ chemical conversion coatings; schematic diagram of the $\mathbf{c} \mathrm{Zn}$ and $\mathbf{d}$ chemical conversion coatings in the wax deposition test (after Liang et al. 2016b) 
(a)

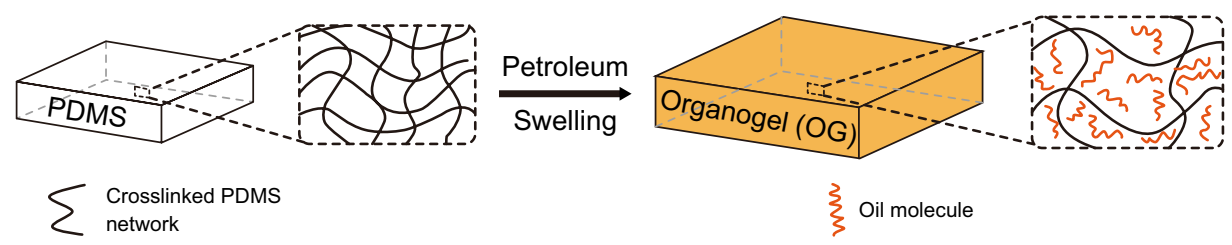

(b)

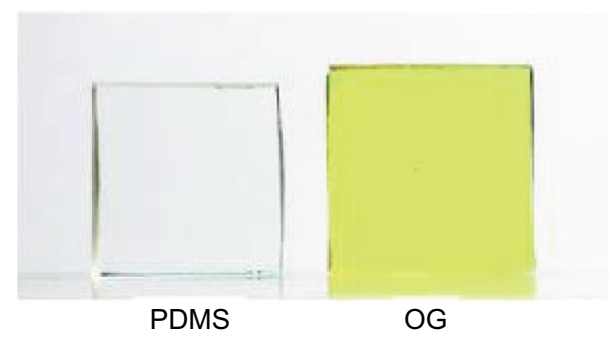

(c)

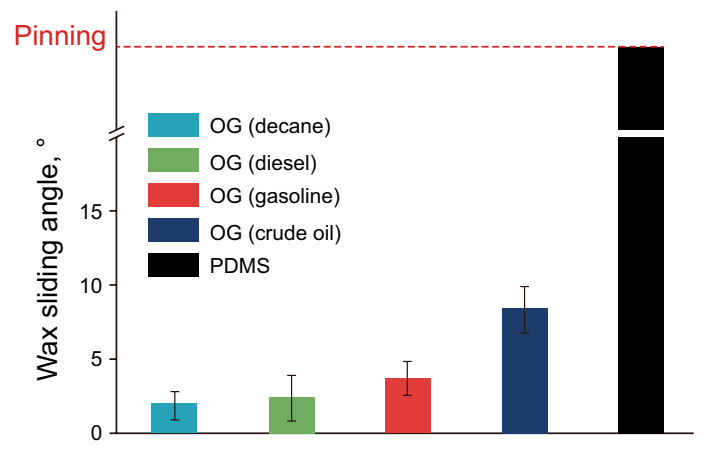

(d)
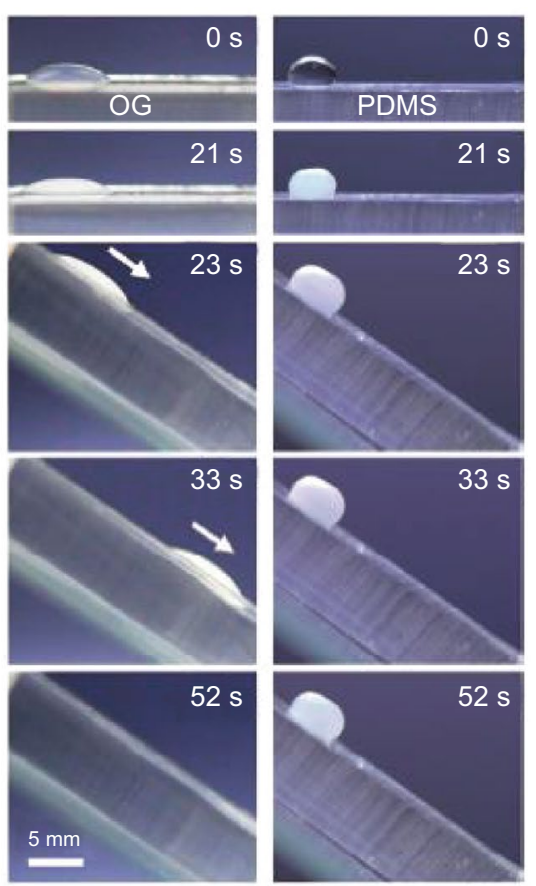

Fig. 10 a Cross-linked PDMS soaked in oil and expanded. b OG is transparent after expansion. c Comparison of adhesion of wax on the PDMS surface after soaking in different petroleum products. d Comparison of the adhesion of wax on the surface of OG and PDMS (after Yao et al. 2015)

self-reinforcing effect in flowing crude oil. Just as fish and pitcher plants use the surrounding water, the organogel can absorb the light components of the crude oil to achieve selfreinforcement. As a result, this coating may have long-term resistance to wax deposition and good mechanical stability.

These organogel coatings not only have the advantages of simple preparation and excellent performance, but also provide a new method of preparing ultra-low adhesion surfaces. In the future of machinery manufacturing, environmental protection, shipbuilding and other fields, this coating technique will have great prospects.

\section{Conclusions and outlook}

In the modern petroleum industry, the most advanced techniques of low surface energy anti-wax coatings have been put into practice. From the initial phenolic resin coating to the current ethylenetetrafluoroethylene, low surface coatings with surface energy reduction help the anti-wax effect continue to improve. However, with the exploration and development of offshore oil, the harsh conditions and the change of environmental factors, higher requirements for crude oil pipeline coatings are put forward. They will not only need better anti-wax and anti-scaling effects, but also need to provide long-term stability for protection, in order to ensure the normal exploitation and transportation of petroleum.

In recent years, more attention has been paid to the interfacial wettability between coatings and crude oil. Novel functional coatings have been designed by using bionic concepts, including superhydrophilic micro-nanostructure composite coatings and self-reinforcing ultra-low adhesion surfaces. The research and preparation of these new materials not only provide us with new ideas, but also improve the comprehensive properties, such as mechanical properties, corrosion resistance and efficient stability.

In the future research and development of anti-wax coatings, the bioinspired intelligent interfacial materials have great research potential for the state of multiphase 
mixed flow of oil and water. Of course, the performance of new coatings will also become more and more multifunctional. They must not only provide efficient and stable properties to prevent wax deposition, but also have corrosion resistance, low-temperature resistance, scour resistance and excellent mechanical properties. Henceforth, only with many excellent comprehensive properties can the novel anti-wax coatings effectively solve the problem of wax deposition in crude oil pipelines for a long time.

Open Access This article is distributed under the terms of the Creative Commons Attribution 4.0 International License (http://creativeco mmons.org/licenses/by/4.0/), which permits unrestricted use, distribution, and reproduction in any medium, provided you give appropriate credit to the original author(s) and the source, provide a link to the Creative Commons license, and indicate if changes were made.

\section{References}

Aiyejina A, Chakrabarti DP, Pilgrim A, Sastry MKS. Wax formation in oil pipelines: a critical review. Int J Multiph Flow. 2011;37(7):671-94. https://doi.org/10.1016/j.ijmultiphaseflo w.2011.02.007.

Azevedo LFA, Teixeira AM. A critical review of the modeling of wax deposition mechanisms. Pet Sci Technol. 2003;21(3-4):393-408. https://doi.org/10.1081/LFT-120018528.

Bae TH, Kim IC, Tak TM. Preparation and characterization of fouling-resistant $\mathrm{TiO}_{2}$ self-assembled nanocomposite membranes. J Membr Sci. 2006;275(1):1-5. https://doi.org/10.1016/j.memsc i.2006.01.023.

Bai F, Wu JT, Gong GM, Guo L. Biomimetic "cactus spine" with hierarchical groove structure for efficient fog collection. Adv Sci. 2015. https://doi.org/10.1002/advs.201500047.

Brown TS, Niesen VG, Erickson DD. The effects of light ends and high pressure on paraffin formation. In: SPE annual technical conference and exhibition, 25-28 September, New Orleans, Louisiana; 1994. https://doi.org/10.2118/28505-ms.

Burger ED, Perkins TK, Striegler JH. Studies of wax deposition in the Trans Alaska pipeline. J Pet Technol. 1981;33(6):1075-86. https ://doi.org/10.2118/8788-PA.

Charles JG. Unique paraffin inhibition technique reduces well maintenance. J Can Pet Technol. 1986;25(2):22. https://doi. org/10.2118/86-04-04.

Chen KL, Zhou SX, Wu LM. Self-healing underwater superoleophobic and anti-biofouling coatings based on the assembly of hierarchical microgel spheres. ACS Nano. 2016;10(1):1386. https://doi. org/10.1021/acsnano.5b06816.

Cheng QF, Li MZ, Zheng YM, Su B, Wang ST, Jiang L. Janus interface materials: superhydrophobic air/solid interface and superoleophobic water/solid interface inspired by a lotus leaf. Soft Matter. 2011;7(13):5948-51. https://doi.org/10.1039/C1SM05452J.

Correra S, Fasano A, Fusi L, Primicerio M. Modelling wax diffusion in crude oils: the cold finger device. Appl Math Model. 2007;31(10):2286-98. https://doi.org/10.1016/j.apm.2006.09.007.

Couto GH, Chen H, Delle-Case E, Sarica C, Volk M. An investigation of two-phase oil/water paraffin deposition. SPE Prod Oper. 2008;23(1):49-55. https://doi.org/10.2118/114735-PA.

Danilović DS, Karović-Maričić VD, Čokorilo VB. Solving paraffin deposition problem in tubing by heating cable application. Therm Sci. 2010;14(1):247-53. https://doi.org/10.2298/TSCI1001247D.
Dotto MER, Camargo SS. Scaling law analysis of paraffin thin films on different surfaces. J Appl Phys. 2010;107(1):014911-6. https ://doi.org/10.1063/1.3280009.

Dotto MER, Martins RN, Ferreira M, Camargo SS. Influence of hydrogenated amorphous carbon coatings on the formation of paraffin deposits. Surf Coat Technol. 2006;200(22):6479-83. https://doi. org/10.1016/j.surfcoat.2005.11.061.

Duan JM, Gong J, Zhang Y. Research progress into wax deposition in multiphase mixed transmission pipelines. Oil Gas Storage Transp. 2011;30(4):241-8 (in Chinese).

Gao SJ, Sun JC, Liu PP, Zhang F, Zhang WB, Yuan SL et al. A robust polyionized hydrogel with an unprecedented underwater anticrude-oil-adhesion property. Adv Mater. 2016;28(26):5307-14. https://doi.org/10.1002/adma.201600417.

Gilles V, Vieira MA, Lacerda V, Castro EVR, Santos RB, Orestes E, Carneiro JWM, Greco SJ. A new, simple and efficient method of Steglich esterification of juglone with long-chain fatty acids: synthesis of a new class of non-polymeric wax deposition inhibitors for crude oil. J Braz Chem Soc. 2015;26(1):74-83. https:// doi.org/10.5935/0103-5053.20140216.

Gonçalves JL, Bombard AJF, Soares DAW, Alcantara GB. Reduction of paraffin precipitation and viscosity of Brazilian crude oil exposed to magnetic fields. Energy Fuels. 2010;24(5):3144-9. https://doi.org/10.1021/ef901302y.

Gong GM, Wu JT, Liu JG, Sun N, Zhao Y, Jiang L. Bio-inspired adhesive superhydrophobic polyimide mat with high thermal stability. J Mater Chem. 2012;22(17):8257-62. https://doi.org/10.1039/ C2JM16503A.

Gong GM, Wu JT, Jin X, Jiang L. Adhesion tuning at superhydrophobic states: from petal effect to lotus effect. Macromol Mater Eng. 2015a;300(11):1057-62. https://doi.org/10.1002/mame.20150 0143.

Gong GM, Zhou C, Wu JT, Jin X, Jiang L. Nanofibrous adhesion: the twin of gecko adhesion. ACS Nano. 2015b;9(4):3721-7. https:// doi.org/10.1021/nn5063112.

Guo TQ, Heng LP, Wang MM, Wang J, Jiang L. Robust underwater oil-repellent material inspired by columnar nacre. Adv Mater. 2016;28(38):8505-10. https://doi.org/10.1002/adma.201603000.

Guo YZ, Li WP, Zhu LQ, Liu HC. An excellent non-wax-stick coating prepared by chemical conversion treatment. Mater Lett. 2012a;72(4):125-7. https://doi.org/10.1016/j.matlet.2011.12.079.

Guo YZ, Li WP, Zhu LQ, Wang ZW, Liu HC. Phosphoric chemical conversion coating with excellent wax-repellent performance. Appl Surf Sci. 2012b;259(16):356-61. https://doi.org/10.1016/j. apsusc.2012.07.051.

Hamouda A, Ravney J. Prediction of wax deposition in pipelines and field experience on the influence of wax on drag-reducer performance. In: Offshore technology conference, 4-7 May, Houston, TX; 1992. https://doi.org/10.4043/7060-MS.

He ZG, Mei BW, Wang WT, Sheng JY, Zhu SY, Wang L et al. A pilot test using microbial paraffin-removal technology in Liaohe oilfield. Pet Sci Technol. 2003;21(1-2):201-10. https://doi. org/10.1081/lft-120016942.

Hernandez OC, Hensley H, Sarica C, Brill JP, Volk M, Delle-Case E. Improvements in single-phase paraffin deposition modeling. SPE Prod Facil. 2004;19(4):237-44. https://doi.org/10.2118/84502 -PA.

Huang QY, Bi Q, Li N. Research progress into wax deposition in oilwater two-phase flow. Chem Ind Eng Progr. 2016;35(S1):69-74. https://doi.org/10.16085/j.issn.1000-6613.2016.s1.013 (in Chinese).

Jessen FW, Howell JN. Effect of flow rate on paraffin accumulation in plastic, steel, and coated pipe. Soc Pet Eng J. 1958;213(4):80-4.

Jorda RM. Paraffin deposition and prevention in oil wells. J Pet Technol. 1966;18(12):1605-12. https://doi.org/10.2118/1598-PA. 
Jung T, Kim JN, Kang SP. Influence of polymeric additives on paraffin wax crystallization in model oils. Korean J Chem Eng. 2016;33(6):1813-22. https://doi.org/10.1007/s11814-016-0052-3.

Lei Y, Han SP, Zhang JJ. Effect of the dispersion degree of asphaltene on wax deposition in crude oil under static conditions. Fuel Process Technol. 2016;146:20-8. https://doi.org/10.1016/j.fupro c.2016.02.005.

Li CX, Bai F, Wang Y. Influence of crude oil composition on wax deposition on tubing walls. CIESC J. 2014;65(11):4571-8 (in Chinese).

Li CX, Cai JY, Yang F, Zhang Y, Bai F, Ma YY et al. Effect of asphaltenes on the stratification phenomenon of wax-oil gel deposits formed in a new cylindrical Couette device. J Pet Sci Eng. 2016;140:73-84. https://doi.org/10.1016/j.petrol.2016.01.004.

Li MY, Su JG, Wu ZL, Yang YD, Ji SL. Study of the mechanisms of wax prevention in a pipeline with glass inner layer. Colloids Surf A Physicochem Eng Asp. 1997;s123-124(96):635-49. https://doi. org/10.1016/s0927-7757(96)03776-4.

Li WP, Zhu LQ, Liu HC, Zhai JY. Preparation of anti-wax coatings and their anti-wax property in crude oil. J Pet Sci Eng. 2013;103(2):80-4. https://doi.org/10.1016/j.petrol.2013.01.013.

Liang WT, Zhu LQ, Li WP, Yang X, Xu C, Liu HC. Bio-inspired composite coating with extreme underwater superoleophobicity and good stability for wax prevention in petroleum industry. Langmuir ACS J Surf Colloids. 2015;31(40):11058-66. https:// doi.org/10.1021/acs.langmuir.5b03234.

Liang WT, Zhu LQ, Xu C, Li WP, Liu HC. Facile fabrication of antiwax conversion coatings based on water film theory. Mater Lett. 2016a;176:56-9. https://doi.org/10.1016/j.matlet.2016.04.019.

Liang WT, Zhu LQ, Xu C, Li WP, Liu HC. Ecologically friendly conversion coatings with special wetting behaviors for wax prevention. RSC Adv. 2016b;6(31):26045-54. https://doi.org/10.1039/ C6RA00611F.

Liu JH, Jia YP, Xu RD. Microbial prevention of wax deposition in crude oil. Adv Mater Res. 2012;550-553:1364-8. https://doi. org/10.4028/www.scientific.net/AMR.550-553.1364.

Liu MJ, Wang ST, Wei ZX, Song YL, Jiang L. Bioinspired design of a superoleophobic and low adhesive water/solid interface. Adv Mater. 2009;21(6):665-9. https://doi.org/10.1002/adma.20080 1782.

Lu WZ, Zhang SZ. Characteristics of crude oil composition in China. Acta Pet Sin. 1980;1(1):92-105 (in Chinese).

Lu YD, Huang ZY, Hoffmann R, Amundsen L, Fogler HS. Counterintuitive effects of the oil flow rate on wax deposition. Energy Fuels. 2012;26(7):4091-7. https://doi.org/10.1021/ef3002789.

Ma W, Xu H, Takahara A. Substrate-independent underwater superoleophobic surfaces inspired by fish-skin and mussel-adhesives. Adv Mater Interf. 2014. https://doi.org/10.1002/admi.201300092.

Parker AR, Lawrence CR. Water capture by a desert beetle. Nature. 2001;414(6859):33-4. https://doi.org/10.1038/35102108.

Poole GL, Brock G, Szymczak S, Casey G. Successful pipeline cleanout: lessons learned from cleaning paraffin blockage from a deepwater pipeline; 2008. https://doi.org/10.2118/115658-ms.

Quintella CM, Musse APS, Castro MTPO, Scaiano JC, Mikelsons L, Watanabe YN. Polymeric surfaces for heavy oil pipelines to inhibit wax deposition: PP, EVA28, and HDPE. Energy Fuels. 2006;20(2):620-4. https://doi.org/10.1021/ef050267p.

Rashidi M, Mombekov B, Marhamati M. A study of a novel inter pipe coating material for paraffin wax deposition control and comparison of the results with current mitigation technique in oil and gas industry. In: Offshore technology conference Asia, 22-25 March, Kuala Lumpur, Malaysia; 2016. https://doi.org/10.4043/26695 -MS.

Ridzuan N, Adam F, Yaacob Z. Evaluation of the inhibitor selection on wax deposition for Malaysian crude oil. Pet Sci
Technol. 2016;34(4):366-71. https://doi.org/10.1080/10916 466.2015.1127971.

Samigullin AD, Galiakbarov AT, Galiakbarov RT. Study of the petroleum schedules thermal cleaning process from asphalt, resin and paraffin deposits using low-temperature plasma. J Phys: Conf Ser. 2016. https://doi.org/10.1088/1742-6596/669/1/012017.

Sarica C, Panacharoensawad E. Review of paraffin deposition research under multiphase flow conditions. Energy Fuels. 2012;26(7):3968-78. https://doi.org/10.1021/ef300164q.

Seow WK. Comparison of ultrasonic and mechanical cleaning of primary root canals using a novel radiometric method. Pediatr Dent. 1991;13(3):136-41.

Singh P, Venkatesan R, Fogler HS, Nagarajan N. Formation and aging of incipient thin film wax-oil gels. AIChE J. 2000;46(5):1059-74. https://doi.org/10.1002/aic.690460517.

Sun XJ, Lv T, Xiao R. Cleaning and preventing wax technology in waxy crude oil pipelines. Clean World. 2014;30(4):31-4 (in Chinese).

Tian Z, Jin WB, Wang L, Jin Z. The study of temperature profile inside wax deposition layer of waxy crude oil in pipeline. Front Heat Mass Transf. 2014. https://doi.org/10.5098/hmt.5.5.

Tissot BP, Welete DH, Xiong SS. Composition, classification of crude oil and influence of geological factors on crude oil composition. Pet Exp Geol. 1978;4:50-116 (in Chinese).

Towler BF, Rebbapragada S. Mitigation of paraffin wax deposition in Cretaceous crude oils of Wyoming. J Pet Sci Eng. 2004;45(12):11-9. https://doi.org/10.1016/j.petrol.2004.05.006.

Tung N, Vuong N, Quang KB, Vinh N, Hung P, Hue V et al. Studying the mechanism of magnetic field influence on paraffin crude oil viscosity and wax deposition reductions. 2001. https://doi. org/10.2118/68749-ms.

Venkatesan R, Östlund JA, Chawla H, Wattana P, Nydén M, Fogler HS. The effect of asphaltenes on the gelation of waxy oils. Energy Fuels. 2003;17(6):1630-40. https://doi.org/10.1021/ef034013k.

Wang LJ, Zhang XJ. The methods and apparatus of laboratory evaluation of drag reduction, viscosity reduction and anti-wax effects in transportation of crude oil in pipelines. Chem Eng Oil Gas. 1999;28(3):199-202 (in Chinese).

Wang ZW, Zhu LQ, Liu HC, Li WP. A conversion coating on carbon steel with good anti-wax performance in crude oil. J Pet Sci Eng. 2013a;112(3):266-72. https://doi.org/10.1016/j.petro 1.2013.11.013.

Wang ZW, Zhu LQ, Li WP, Liu HC. Bioinspired in situ growth of conversion films with underwater superoleophobicity and excellent self-cleaning performance. ACS Appl Mater Interfaces. 2013b;5(21):10904. https://doi.org/10.1021/am4030966.

Xiao M, Li WH, Lu M, Zhang ZZ, Luo YJ, Qiao W, Sun SS, Zhong WZ, Zhang M. Effect of microbial treatment on the prevention and removal of paraffin deposits on stainless steel surfaces. Biores Technol. 2012;124:227-32. https://doi.org/10.1016/j.biort ech.2012.07.063.

Xu LP, Peng JT, Liu YB, Wen YQ, Zhang XJ, Jiang L et al. Nacreinspired design of mechanical stable coating with underwater superoleophobicity. ACS Nano. 2013;7(6):5077. https://doi. org/10.1021/nn400650f.

Yang F, Cai JY, Cheng L, Li CX, Ji ZY, Yao B et al. Development of asphaltenes triggered two-layer waxy oil gel deposit under laminar flow: an experimental study. Energy Fuels. 2016. https://doi. org/10.1021/acs.energyfuels.6b01482.

Yang F, Zhao YS, Sjöblom J, Li CX, Paso KG. Polymeric wax inhibitors and pour point depressants for waxy crude oils: a critical review. J Dispersion Sci Technol. 2015;36(2):213-25. https://doi. org/10.1080/01932691.2014.901917.

Yao X, Wu SW, Chen L, Ju J, Gu ZD, Liu MJ et al. Self-replenishable anti-waxing organogel materials. Angew Chem Int Ed. 2015;54(31):8975-9. https://doi.org/10.1002/anie.201503031. 
Yi SJ, Hu K, Li B, Yang JX, Zhang W. Field application of the technology of microbial paraffin cleaning and prevention in high temperature and hyperhaline wells. Jianghan Oilfield. J Oil Gas Technol. 2009;31(4):146-8 (in Chinese).

Yu JG, Zhao XJ, Jimmy CY, Zhong GR, Han JJ, Zhao QN. The grain size and surface hydroxyl content of super-hydrophilic $\mathrm{TiO}_{2} / \mathrm{SiO}_{2}$ composite nanometer thin films. J Mater Sci Lett. 2001;20(18):1745-8. https://doi.org/10.1023/A:1012458411717.

Zhang GZ, Liu G. Study on the wax deposition of waxy crude in pipelines and its application. J Pet Sci Eng. 2010;70(1):1-9. https:// doi.org/10.1016/j.petrol.2008.11.003.
Zhang XJ, Tian J, Wang LJ, Zhou ZF. Wettability effect of coatings on drag reduction and paraffin deposition prevention in oil. J Pet Sci Eng. 2002;36(1-2):87-95. https://doi.org/10.1016/S0920 $-4105(02) 00267-X$.

Zheng XH. Research and application into oil-tube paraffin removal technology by electrical heating. Technol Superv Pet Ind 2012;28(1):6-8 (in Chinese). 